\title{
Drivers of academic engagement in public-private research collaboration: an empirical study
}

\author{
Giovanni Abramo ${ }^{1}$ (D) Ciriaco Andrea D'Angelo ${ }^{2}$
}

Accepted: 9 September 2021 / Published online: 18 October 2021

(c) The Author(s) 2021

\begin{abstract}
University-industry research collaboration is one of the major research policy priorities of advanced economies. In this study, we try to identify the main drivers that could influence the propensity of academics to engage in research collaborations with the private sector, in order to better inform policies and initiatives to foster such collaborations. At this purpose, we apply an inferential model to a dataset of 32,792 Italian professors in order to analyze the relative impact of individual and contextual factors affecting the propensity of academics to engage in collaboration with industry, at overall level and across disciplines. The outcomes reveal that the typical profile of the professor collaborating with industry is a male under age 40, full professor, very high performer, with highly diversified research, and who has a certain tradition in collaborating with industry. This professor is likely to be part of a staff used to collaborating with industry, in a small university, typically a polytechnic, located in the north of the country.
\end{abstract}

Keywords University-industry interactions - Research collaboration - Technology transfer . Individual and contextual factors $\cdot$ Co-authorship $\cdot$ Bibliometrics

JEL Classification O32-Management of Technological Innovation and R\&D

\section{Introduction}

Increasingly, the capacity of a nation to produce wealth depends on investment in strengthening the so-called 'triangle of knowledge': research, education and innovation. Many studies show that competitive capacity is favored by policies that stimulate technological transfer and incentivize osmosis between the worlds of academic research

Giovanni Abramo

giovanni.abramo@uniroma2.it

Ciriaco Andrea D’Angelo

dangelo@dii.uniroma2.it

1 Laboratory for Studies in Research Evaluation at the Institute for System Analysis and Computer Science (IASI-CNR), National Research Council of Italy, Via dei Taurini 19, 00185 Roma, Italy

2 Dipartimento di Ingegneria dell'Impresa, Laboratory for Studies in Research Evaluation (IASI-CNR), University of Rome "Tor Vergata" - Italy, Via del Politecnico 1, 00133 Roma, Italy 
and industry (Fan et al., 2015; Shane, 2004; Thursby \& Thursby, 2003; Mowery et al., 2001). Indeed, all industrially-developed nations have identified cross-sector co-operation as a major policy priority.

Scholars in the economics of innovation have extensively analyzed the development of public-private interaction. The relations between the two sectors take form through various modalities and can differ in their degree of formalization (Perkmann et al., 2013), with typical paths including joint research projects, the award of research contracts, licensing and award of know-how and patents, and through consulting, training services and professional mobility. The observation of such modalities, their empirical study and analysis of their underlying determinants, can provide useful cognitive bases for the policy maker and for research managers called to stimulate them.

One of the main modes of knowledge osmosis is through public-private research collaboration. The studies investigating this phenomenon have inquired into a range of subjects. One line of research concerns the identification of individual and institutional motivations, thereby permitting analysis of the drivers of collaboration. The determinants of variety and frequency of public-private interactions lie above all in the characteristics of the individual researcher, much more than those of their home organizations (D'Este \& Patel, 2007), but these are also affected by the disincentive of transaction costs, increasing with greater cultural and motivational differences between partners (Belkhodja \& Landry, 2007; Drejer \& Jørgensen, 2005).

Within this research stream, we intend to contribute on the main drivers that could influence the propensity of academics to engage in research collaborations with the private sector, and how they differ across disciplines. Previous studies investigating this phenomenon have generally resorted to surveys, which embed severe limits on the scale of observations. To overcome these, we adopt a bibliometric approach. The bibliometric method assumes that co-authorship of scientific publications certifies research collaborations, even though not all co-authored publications reveal a true research collaboration, and not all research collaborations bring to co-authored scientific publications (Katz \& Martin, 1997). Further considerations are that industry relies heavily on collaboration with academia in publishing papers, but not in patenting, while academia rarely turns to industry in matters of research publication or patent applications (Huang et al., 2015). Observing publications and disambiguating their authors allow large scale analyses, stratified per individual and contextual characteristic. A further strength of the bibliometric approach is that it allows conducting fine-grained analyses at field level. Large scale observations strengthen significancy of results at field level, which is hard to achieve through surveys.

We consider three sets of determinants of the propensity of university-industry collaboration at individual level. First, because social aspects are at play (Llopis et al., 2018), we expect that individual traits (e.g. age, gender, academic rank, and research performance) will have an influence. Second, we also expect that contextual factors, particularly those of the nature, size and location of a university, could influence the frequency and scope of opportunities for academics to personally interact with colleagues in industry (Zhao et al., 2020). Finally, few scholars have examined whether and how scientists' motives to engage in collaboration with industry differ across fields (Cohen et al., 2002; D'Este \& Perkmann, 2011; Lim, 2004). It is known that the research production function varies across scientific domains (Abramo et al., 2013a, 2013b), therefore we also expect significant discipline effects on the propensity of university-industry collaborations, certainly more noticeable in applied-science disciplines than theoretical ones (Cohen et al., 2020). 
Our research questions can therefore be summarized as:

- What is the typical profile of academic professors who collaborate with the private sector?

- Which individual and contextual drivers have the greatest impact on the propensity for research collaboration with the private sector?

- How does the importance of such drivers vary across research fields?

To address these questions, we adopt a statistical approach, applying an inferential model on a dataset of 32,792 professors working in Italian universities, in the hard sciences. This is the first study on individual-level collaboration based on bibliometric techniques, which allow large-scale investigations and cross-field analysis. We exclude arts and humanities because coverage of relevant output in bibliographic repertories is insufficient to allot reliable bibliometric analyses. We expect though that university-industry collaborations in these disciplines are comparatively much lower. Alongside, higher collaboration propensity is expected in those fields where traditional research is closer to market applications. Policy and management implications of field differences when designing incentives, assessment and rewarding are relevant.

As noted, all industrially developed countries, in various ways, have enacted policy programs incentivizing university-industry collaboration. In recent years, Italy has followed the example of the UK research evaluation framework (REF), by enacting national research assessment exercises (VQRs) for evaluation of university 'third mission' activities, which then support allocation of public funding.

By focusing on university researchers and the factors influencing their interactions with industry, we can improve our understanding about who in academia interacts with industry (Bercovitz \& Feldman, 2003). The empirical evidence from our study can serve decision makers engaged in formulating policies and incentive systems, intended to foster university-industry knowledge flows. Ex post, they can support assessment of the effectiveness of existing incentives, net of the determinants of individual propensity to engage in crosssector collaborations.

The next section of this work provides a review of previous studies on the determinants of private-public research collaboration. Section three presents the dataset and describes the methodology adopted. The fourth section presents and comments the results of the analysis. The work concludes with a discussion of the findings and their implications for research policies.

\section{Theoretical framework}

Research collaboration between university and industry has positive effects in economic growth, social value, and competitiveness. Observing this, policy makers have increased their efforts to promote public-private interactions, acting on both sides of the partnerships through: (i) research policies intended to promote the so-called third mission of universities (Iorio et al., 2016); (ii) innovation policies that encourage companies to interact with public research organizations (Guimón \& Paunov, 2019; Perkmann et al., 2013).

The underlying motivations for public-private co-operation are different for the two partners. Private enterprise is interested in collaborating with the public sector for access to skills, with which to create new knowledge for aims of commercial exploitation (Bekkers \& Bodas Freitas, 2008; Perkmann et al., 2013). On the other side, academics benefit 
from accessing instrumental assets, but also gain direct economic and financial benefits of different kinds (Garcia et al., 2020). Cross-sector collaborations involve costs as well, both tangible and intangible (opportunity costs). Therefore, the propensity and intensity of public-private interactions depend on the balance between costs and benefits of such relationships.

Previous literature has focused almost entirely on observation of the phenomenon from the perspective of the academic researcher, generally through surveys on small national samples: 564 Chinese scientists in Zhao et al. (2020); 178 academics in Sri Lanka in Weerasinghe and Dedunu (2020); 1295 researchers active at the Spanish National Research Council in Llopis et al. (2018); 4400 Norwegian academics in Thune et al. (2016); 4337 UK engineering and physics scientists in D'Este and Patel (2007). Such surveys indicate that propensity and extent of engagement by public researchers in joint research project with industry is influenced by several variables, some referring to the individual characteristics of the researcher, others to their context of operation.

\subsection{Individual characteristics}

Many studies reveal a correlation between the propensity to collaborate with companies and the career cycle of an academic, although the impact of age itself seems non-linear (Weerasinghe \& Dedunu, 2020). One might think that because of their greater social capital, older researchers would have more intense and diversified collaborative activities (Bozeman \& Corley, 2004). In fact, collaborations tend to grow most strongly early in the scientist's career, as they begin to establish a reputation, but seem to decline in the later stages, possibly as the initial incentives drop off (Bozeman \& Gaughan, 2011; Ubfal \& Maffioli, 2011). Younger academics are also pushed to collaborate to overcome disadvantages in availability of resources, and to demonstrate their capacity to activate and manage collaborations, considered essential to career progress (Bayer \& Smart, 1991; Traoré \& Landry, 1997).

Age and academic rank are strongly correlated, given the linkages between seniority and promotion mechanisms. However, in this type of study the effect of age should be separated from effect of researcher status. All others being equal, the academic rank of a scientist, attesting their authority in the community of reference, impacts on their ability to attract the interest of private companies (Abramo et al., 2014; D’Este \& Patel, 2007).

Gender, in general, also plays an important role in the propensity and intensity of collaborations, and in particular for cross-sector collaborations. The overall representation of women in research is increasing, but inequality remains. Mechanisms of gender homophily would clearly contribute to the greater difficulty of women in developing their social capital, and therefore accessing top positions, research funding and collaboration networks (Boschini \& Siogren, 2007). Analyzing a large sample of UK physics and engineering scientists, Tartari and Salter (2015) argue that women academics engage less in collaboration activities with industry than male colleagues of similar status, as well as in different ways. Calvo et al. (2019) trace the male/female gap to motivational reasons: surveying a sample of 420 research groups of eight regions of Spain, France and Portugal, they found that research groups led by women have lower probability of showing interest in R\&D cooperation with firms.

The early behaviour of an individual academic in joint research with industry generates a strong imprint, leading to expectations of continuing knowledge transfer practices (Bercovitz \& Feldman, 2003). The research quality of the academic and their activity in technology transfer are found to be positively related (Mansfield, 1995; Mansfield \& 
Lee, 1996). Generally, the link between research collaboration and performance is amply accepted in the literature (He et al., 2009; Lee \& Bozeman, 2005; Schartinger et al., 2001). Although the causal nexus appears complex and variable (Abramo et al., 2017), it is logical that there would be positive correlation between a professor's scientific performance and the propensity of their collaboration with private companies, who on the other side are searching top partners for their R\&D projects (Balconi \& Laboranti, 2006). However, in a market strongly hampered by information asymmetry, companies could often base their decisions on geographical and social proximity more than on the standing of their potential partners (Abramo et al., 2011a).

Regarding the empirical verification of a possible link between research collaboration and performance, many studies have relied simply on the aggregate profile of the department or institution as a proxy of the research quality of the individual scientists (Perkmann et al., 2011). The current study instead begins with the profile of the individual, including a variable that measures the level of specialization/diversification of the scientist's research activities, a characteristic not previously considered. Regarding the effect of this aspect on the propensity to collaborate with private companies, two opposing hypotheses seem possible: on the one hand, companies could be on the lookout for scientists highly specialized in their fields of interest; on the other hand, a varied and well-sorted scientific portfolio is more likely to intersect with some topic of interest to a private company, on which the academic can graft a joint research project. These are hypotheses that have never been proposed in the literature and therefore constitute one of the novelties of this study.

\subsection{Contextual characteristics}

Clearly, contextual characteristics will have an influence on the academic's propensity to engage in joint research with industry. The university's statement of core mission has a strong effect on the research trajectories of its scientific laboratories. The influence of the 'third mission' on the research agenda of an academic depends on the 'commercial orientation' of their university (Di Gregorio \& Shane, 2003). A university or department with a mission explicitly including collaboration with industry can certainly provide significant motivational stimuli for its individual researchers (Giuri et al., 2019). The step of operating a technology transfer office is generally found to be a positive determinant of collaboration (Phan \& Siegel, 2006), helping in particular to reduce 'cognitive distance' between academics and industry (Muscio \& Pozzali, 2013).

The intensity of overall activity in technology transfer, and of public-private research collaboration in particular, is certainly correlated with the demand for new knowledge expressed by companies in a given territory, meaning that the location of the researcher's home university also affects the possibilities of their collaboration with private colleagues (Berbegal-Mirabent et al., 2015). In Italy, there occurs a significant gap in private R\&D expenditures between north (highly industrialized) and south.

It is plausible that the size of the university department would be related to the propensity of interactions with industry. The absence of a critical mass of staff or assets instrumental to the academic's specific research area could encourage them to seek collaborations with colleagues of other organizations (Schartinger et al., 2001). Scarcity of institutional funding can push departments/groups to pursue an 'income generation strategy' with respect to private sources (Giuri et al., 2019). At the same time, an abundance of industry-sourced funding may signal an environment that favors institutional interaction with private companies (Schartinger et al., 2001). 
Finally, Tartari et al. (2014) argue that 'academic scientists' industry engagement is influenced significantly by the behaviour of their peers, ... through the mechanism of social comparison'. The researcher's engagement will vary in the course of their career, but in any case will be conditioned by the choices of their reference group, both because they find inspiration there and because through conformity, they achieve social approval from their peers.

\section{Data and methods}

The field of observation consists of Italian university professors conducting research in the so-called hard sciences. We exclude the social sciences (apart from psychology) and arts \& humanities because for these the coverage of bibliographic repertories is still insufficient for reliable representation of research output. In the Italian university system all professors are classified in one and only one field (named the scientific disciplinary sector, SDS, 370 in all). Fields are grouped into disciplines (named university disciplinary areas, UDAs, 14 in all). ${ }^{1}$

The analysis dataset consists of all assistants, associate and full professors (34,410 in all), on staff for at least three years in the period 2013-2017, in 201 SDSs (of 10 UDAs), where publications in international journals serve as a reliable proxy for overall research output. The bibliometric dataset was extracted from the Italian Observatory of Public Research, a database developed and maintained by the present authors, and derived under license from the Clarivate Analytics' Web of science (WoS). Beginning from the raw data of the WoS, and applying a complex algorithm to reconcile the authors' affiliations and disambiguate their true identity, each publication (article, article review and conference proceeding) was attributed to the university scientist or scientists that produced it (D'Angelo et al., 2011). ${ }^{2}$

The result of the algorithm application is as follows. 1618 (4.7\%) professors are unproductive in the five years under observation. Of the 32,792 productive professors, the analysis of co-authorship of publications shows that 9005 (27.5\%) professors co-authored at least one publication with industry (Table 1). ${ }^{3}$ At the UDA level, Industrial and information engineering has the highest share of productive professors collaborating with industry (47.5\%), followed by Chemistry (37.4\%). Psychology and Mathematics and computer science are the UDAs with lowest percentages, respectively $5.5 \%$ and $11.0 \%$. It should be noted that D'Este and Patel (2007) found that over $40 \%$ of UK physics and engineering researchers were involved in at least one industry interaction over 2002-2003: the comparable statistic is obtained from Table 1 by collapsing UDAs 2 and 9.

To answer the research questions, we used a logit regression with individual professors as unit of analysis. The dependent variable (y) is a dummy assuming: 1, if professor $i$ coauthored at least one publication with industry; 0 , otherwise.

\footnotetext{
1 A detailed mapping of SDSs and corresponding UDAs can be found at https://www.cun.it/uploads/stori co/settori_scientifico_disciplinari_english.pdf, last accessed on 8 September 2021.

2 The harmonic average of precision and recall (F-measure) of authorships, as disambiguated by the algorithm, is around $97 \%$ (2\% margin of error, $98 \%$ confidence interval).

${ }^{3}$ Collaboration with industry is evidenced by the presence of at least one private company in the address list of publications authored by the professor in the dataset. This implied the manual scrutiny and unification of all bibliographic addresses linkable to a private company with affiliation country 'Italy'.
} 
Table 1 Dataset of the analysis

\begin{tabular}{lrrll}
\hline UDA & SDS & No. of professors & $\begin{array}{l}\text { With at least } \\
\text { one publication }\end{array}$ & $\begin{array}{l}\text { With at least one } \\
\text { publication with } \\
\text { industry }\end{array}$ \\
\hline 1. Mathematics and computer science & 10 & 3083 & $2797(90.7 \%)$ & $308(11.0 \%)$ \\
2. Physics & 8 & 2193 & $2120(96.7 \%)$ & $491(23.2 \%)$ \\
3. Chemistry & 11 & 2844 & $2803(98.6 \%)$ & $1047(37.4 \%)$ \\
4. Earth sciences & 12 & 1031 & $996(96.6 \%)$ & $317(31.8 \%)$ \\
5. Biology & 19 & 4729 & $4599(97.3 \%)$ & $1167(25.4 \%)$ \\
6. Medicine & 50 & 9411 & $8876(94.3 \%)$ & $2029(22.9 \%)$ \\
7. Agricultural and veterinary sciences & 30 & 2978 & $2860(96.0 \%)$ & $791(27.7 \%)$ \\
8. Civil engineering & 9 & 1505 & $1402(93.2 \%)$ & $374(26.7 \%)$ \\
9. Industrial and information engineering & 42 & 5248 & $5081(96.8 \%)$ & $2412(47.5 \%)$ \\
10. Psychology & 10 & 1388 & $1258(90.6 \%)$ & $69(5.5 \%)$ \\
Total & 201 & 34,410 & $32,792(95.3 \%)$ & $9005(27.5 \%)$ \\
\hline
\end{tabular}

Different specifications of the response variable were considered but discarded for the following reasons. The distribution of the number of publications produced in collaboration with the private sector is very skewed: out of the 9005 professors in the dataset, $52 \%$ have only 1 publication in co-authorship with industry; $36 \%$ have 2,3 or $4 ; 12 \%$ have 5 or more (the most prolific professor has 45 publications in co-authorship with industry). We could say that the bottom tier collaborates 'occasionally', the intermediate 'regularly', the top 'intensively', but publication intensity varies across fields, and imposing fixed thresholds would introduce a bias that nullifies the would-be improvement of the measurement of the collaboration intensity. In principle, one could consider the share of publications resulting from collaboration with the private sector out of total publications authored by a professor. But this choice has as many weaknesses: a professor with only one publication, and in collaboration with industry, would show a propensity higher than one with 100 publications, of which 'only' 99 in collaboration. Using the binary specification for the response variable allows us to robustly measure the 'propensity' to collaborate, rather than the 'intensity'. As discussed in Sect. 2, the literature suggests a number of drivers (covariates) that are likely to affect the propensity of professors to engage in research collaboration with industry. We considered the following covariates, grouped in two clusters.

\subsection{Individual covariates}

- Gender $\left(\mathrm{X}_{1}\right)$, specified by a dummy variable (1 for female; 0 for male);

- Age $\left(\mathrm{X}_{2-5}\right)$, specified with 5 classes, through 4 dummies (baseline 'Under 40');

- Academic rank $\left(\mathrm{X}_{6-7}\right)$, specified by 2 dummies (baseline 'Assistant professors');

- Level of specialization of the professor's scientific activity, specified by 2 dummies: 
- 'Highly diversified' $\left(\mathrm{X}_{8}\right), 1$ if the papers falling in the prevalent subject category ${ }^{4}$ of the professor are less than $40 \%$ of total publications; 0 , otherwise; ${ }^{5}$

- 'Highly specialized' $\left(\mathrm{X}_{9}\right), 1$ if the papers falling in the prevalent subject category of the professor are more than $75 \%$ of total publications; 0 , otherwise ${ }^{2}$

- Past behaviour-previous collaborations $\left(\mathrm{X}_{10}\right)$, specified by a dummy variable ( 1 if the professor co-authored at least one publication with industry in 2010-2012; 0, otherwise);

- Total publications authored by the professor in the period under observation $\left(\mathrm{X}_{11}\right)$;

- Research performance as measured by the FSS (fractional scientific strength) indicator: ${ }^{6}$

- $\mathrm{X}_{12}, \mathrm{FSS}$ of the professor, rescaled to the field average;

- $\mathrm{X}_{13}, 1$ if the professor belongs to the top $20 \%$ in his/her field by FSS; 0, otherwise;

\subsection{Contextual covariates}

- Environment-Peers behaviour $\left(\mathrm{X}_{14}\right)$, specified by a dummy variable (1 in case of a colleague in the same university and SDS of the professor, co-authoring publications with industry; 0 , otherwise $) ;^{7}$

- Institutional control $\left(\mathrm{X}_{15}\right)$, specified by a dummy variable ( 0 , for public universities; 1 , for private ones);

- University scope $\left(\mathrm{X}_{16}\right)$, specified by a dummy variable (1, for 'Polytechnics' and 'Schools for Advanced Studies, SS'; 0, otherwise) ${ }^{8}$

- University size in the UDA of the professor $\left(\mathrm{X}_{17-18}\right)$, specified with 3 classes through 2 dummies ('Large', for universities with a research staff in the UDA of the professor, above 80 percentile in the national ranking; 'Medium', with a research staff between 50 and 80 percentile; baseline 'Small');

- University location $\left(\mathrm{X}_{19-22}\right)$, specified with 5 macro-areas, by 4 dummies, baseline 'Islands').

\footnotetext{
${ }^{4}$ The category of each publication refers to the WoS classification scheme accessible at https://images. webofknowledge.com/images/help/WOS/hp_subject_category_terms_tasca.html (last accessed on 8 September 2021). In particular, each publication inherits the subject category (SC, 254 in all) in which the hosting journal is classified. For publications hosted in multi-category journals we adopt the fractional counting of SCs associated to the journal.

5 The chosen thresholds ( $40 \%$ for $\mathrm{X}_{8}$, and $75 \%$ for $\mathrm{X}_{9}$ ) allow for equal partitions of the dataset (one third of of highly diversified professors, and one third of highly specialized ones).

${ }^{6}$ For details on the conceptualization of this indicator as a measure of scientific productivity, also for operational definition, see Abramo \& D'Angelo (2014)

${ }^{7}$ For this variable we do not exclude those publications where the scientist under observation is a coauthor. Such publications are fruit of cross-sector and, at the same time, of 'intramural' collaborations, where the peers effect is at place.

${ }^{8}$ The Italian Minister of University and Research (MUR) recognizes a total of 96 universities as having the legal authority to issue degrees. Of these, 29 are small, private, special-focus universities, of which 13 offer only e-learning; 67 are public and generally multi-disciplinary universities; three are Polytechnics and six are Scuole Superiori (Schools for Advanced Studies), devoted to highly accomplished students, with very small faculties and tightly limited enrolment. In the overall system, $94.9 \%$ of faculty are employed in public universities (0.5\% in Scuole Superiori)
} 
Table 2 Profiling of the Italian academic professor co-authoring publications with industry

\begin{tabular}{|c|c|c|c|c|}
\hline Group variable & Prevailing trait & $\begin{array}{l}\text { Concentra- } \\
\text { tion index }\end{array}$ & Pearson chi-squared & $p$-value \\
\hline Gender & Male & 1.069 & 115.0055 & 0.000 \\
\hline Age & Under 40 & 1.123 & 159.2152 & 0.000 \\
\hline Academic rank & Full professor & 1.134 & 79.4962 & 0.000 \\
\hline UDA & 9-Industrial and inform. engineering & 1.725 & $2.0 \mathrm{e}+03$ & 0.000 \\
\hline Scientific activity & Highly diversified & 1.128 & 146.4991 & 0.000 \\
\hline Past behaviour & Previous collaboration & 2.275 & $2.6 \mathrm{e}+03$ & 0.000 \\
\hline $\begin{array}{l}\text { Research perfor- } \\
\text { mance (FSS } \\
\text { quintile) }\end{array}$ & Top $20 \%$ & 1.434 & $1.2 \mathrm{e}+03$ & 0.000 \\
\hline Environment & Peers collaborating with industry & 1.233 & $1.5 \mathrm{e}+03$ & 0.000 \\
\hline \multirow[t]{2}{*}{ University type } & Public & 1.010 & 33.9566 & 0.000 \\
\hline & Polytechnic or SS & 1.667 & 341.9875 & 0.000 \\
\hline University size & Large & 1.021 & 10.0636 & 0.007 \\
\hline University location & Northwest & 1.163 & 188.1679 & 0.000 \\
\hline
\end{tabular}

In order to control for possible area effects on the propensity to engage in public-private research collaboration by academics, we also considered other 9 dummies related to the ten UDAs under observation.

Through the variables $\mathrm{X}_{15}$ (Institutional control) and $\mathrm{X}_{16}$ (University scope), the authors hope to intercept, although indirectly, the effect known in the literature as the "commercial orientation' of a university. Differently from the literature, our model does not embed the effect of the presence of a technology transfer office, as all Italian universities are required to have one by law. It is possible that the attention and resources devoted to them vary across universities, but we are unable to measure them. All variables were measured at $31 / 12 / 2012$, i.e. the beginning of the period under observation.

\section{Results report}

Table 2 reports the typical profile of the university professor collaborating with private companies, identified by the concentration index on each individual and contextual trait. ${ }^{9}$ The academic is male, under age 40, a full professor, conducting research in Industrial and information engineering, with high scientific productivity (top 20\%) and highly diversified research activity, as well as previous experience in cross-sector collaborations. This professor operates within a group of peers who likewise collaborate with industry, and belongs to a large public university, typically a polytechnic or SSs located in northwestern Italy.

However, the previous descriptive analysis does not take into account the simultaneous effect of all covariates on the independent variable. Therefore, we conduct an inferential analysis using a logit regression model, as illustrated in the previous section. Table 3 shows

\footnotetext{
9 The concentration index is the ratio of two ratios. Example: for the group variable 'gender', the prevailing trait 'male' shows a concentration index of 1.069 , since males compose $70.81 \%$ of total researchers co-authoring publications with industry, and $66.25 \%$ of the total population, therefore 70.81/66.25 $=1.069$.
} 


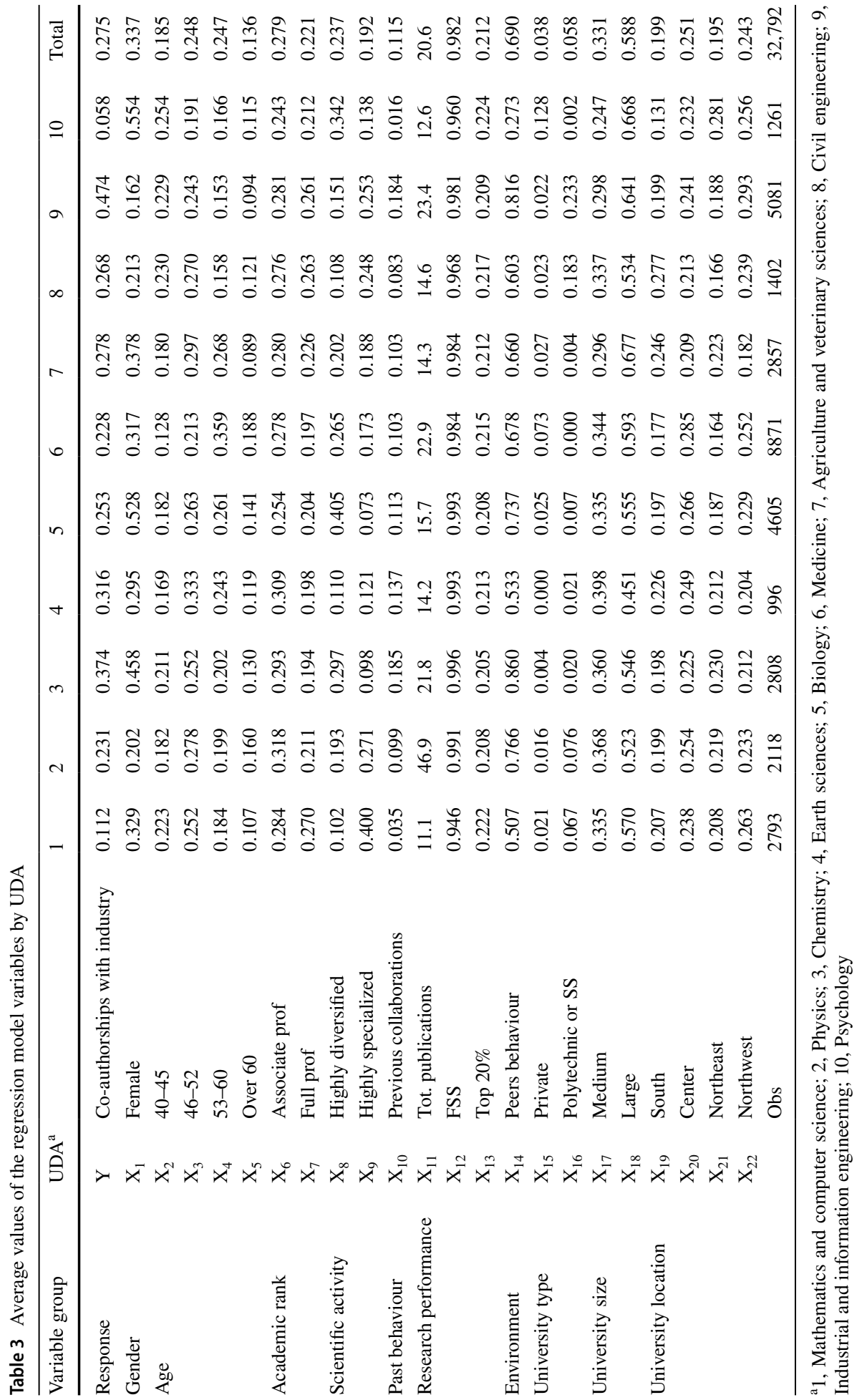




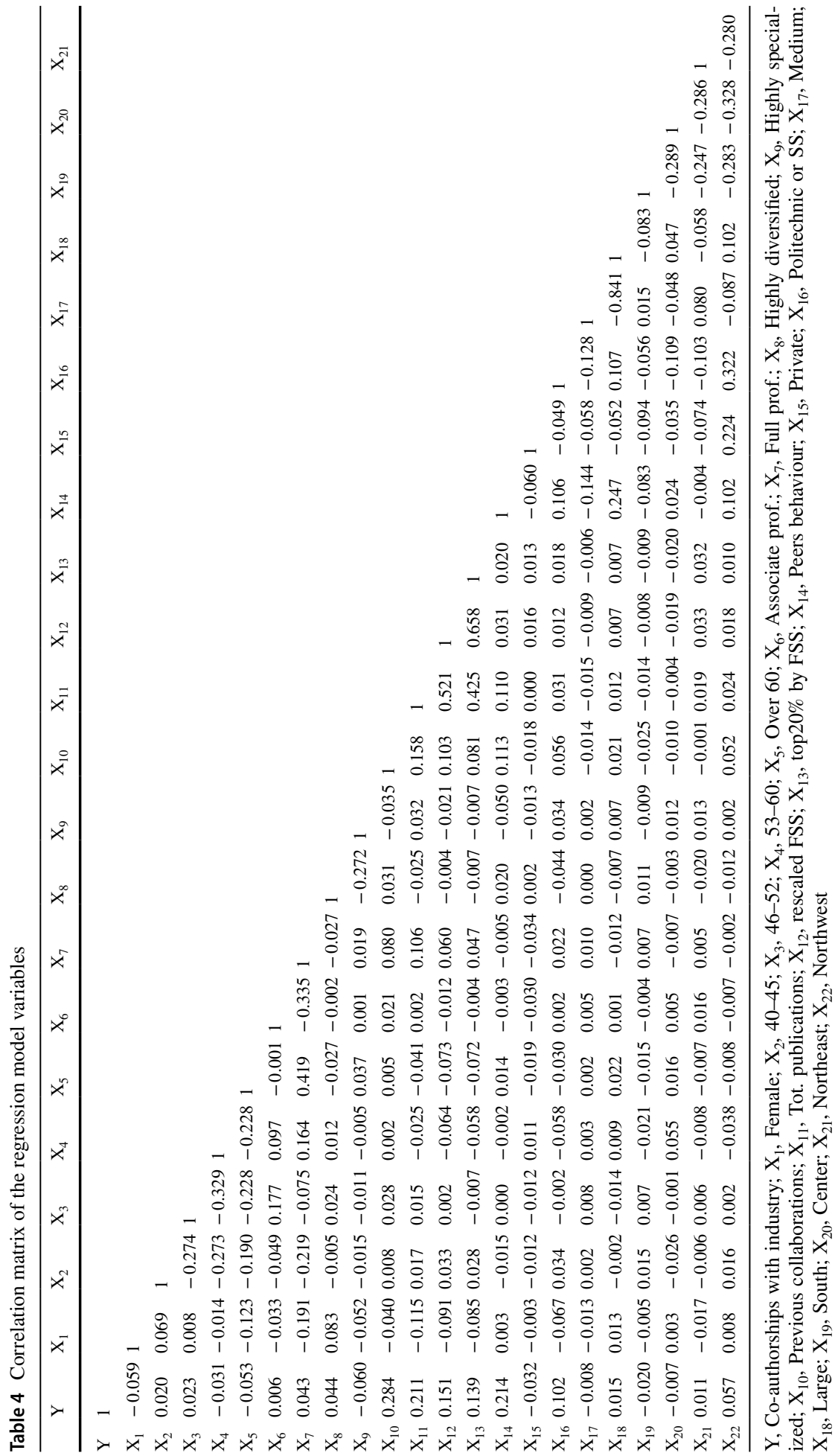


the average values of the model variables, at an overall level and by UDA. Table 4 shows the correlation matrix of the variables, at an overall level. Some significant correlations between pairs of variables (shaded values in Table 4) deserve comment:

$Y$ versus $X_{10}$ (Previous collaborations) As could be expected, the probability of a professor establishing scientific collaborations with the private sectors is strongly influenced by the fact that they have done so before.

$X_{5}$ (Age-over_60) versus $X_{7}$ (Full prof.) It is highly reasonable that age and academic rank would be strongly correlated, and that the attainment of the top level of the academic career takes place on average in old age since, as already mentioned, promotion mechanisms are often linked to seniority (very true in Italy).

$X_{11}$ (Tot. publications) versus $X_{12}$ (rescaled FSS) versus $X_{13}$ (Top 20\%) Output, a fundamental dimension of productivity, is incorporated in FSS together with the impact of each publication and the fractional contribution attributable to each co-author. This trio of variables has the highest correlation index, which calls for checking possible multicollinearity. In reality, as we will see, the co-presence of these covariates does not disturb the model. Rather, $\mathrm{X}_{11}$ acts as an exposure variable, since the publications in collaboration with private companies $(\mathrm{Y})$ are a subset of the total ones $\left(\mathrm{X}_{11}\right)$ : the possible exclusion of this last variable would cause problems of convergence of logit regression.

$X_{14}$ (Peers behaviour) versus $X_{18}$ (University size-Large) Expected correlation, since the probability of a professor having colleagues in the same field, with at least one publication in collaboration with companies, depends on the size of the overall faculty research staff.

$X_{16}$ (University type: Polytechnic or SS) versus $X_{22}$ (University location: Northwest) Reflects a feature typical of the Italian academic system, descending from the facts that the Northwest is the most industrialized area and hosts two of the country's three polytechnics.

Table 5 presents the results of the logit regression. For simpler representation, the coefficients for UDA dummies are omitted. The in-depth analysis by UDA is reported at Table 6 . The model estimation appears very satisfactory. The mean VIF is 2.45 , with maximum (6.99) for the covariate University size-Large, which excludes the presence of multicollinearity that could disturb the estimation of the coefficients. The value of under ROC area (AUC) is 0.77 , which indicates good ability of the model to correctly classify professors, discriminating the propensity to collaborate with companies ${ }^{10}$ in function of individual traits and context.

The estimated coefficients of the regression model are expressed in terms of odds ratios: the reference value is equal to one and indicates that the variable considered has no effect on the Y, i.e. on the probability that a professor has or has not collaborated with private companies. For values above one, the variable instead has a positive marginal effect, and vice versa. The data of column 7, Table 5 indicate that all the covariates have a statistically significant effect.

Among the individual characteristics, gender has a non-marginal effect, as women show a lower propensity to collaborate with private companies than men. Age seems to have a systematically negative impact on the response variable of the proposed model, while academic rank and intensity of research diversification show positive effects. The

\footnotetext{
10 The AUC analysis evaluates a classifier's ability to discern between true positives and false positives. In our case, the AUC value, between 0 and 1, is equivalent to the probability that the result of the logit classifier applied to a researcher randomly extracted from the group of those who collaborated with industry is higher than that obtained by applying it to a researcher randomly extracted from the group of those who did not collaborate (Bowyer et al., 2001).
} 
Table 5 The main drivers of the propensity to collaborate with industry by Italian professors

\begin{tabular}{|c|c|c|c|c|c|c|c|c|}
\hline \multirow[b]{2}{*}{ Variable group } & \multirow[b]{3}{*}{$X_{1}$} & \multirow[b]{2}{*}{ Const } & \multirow{2}{*}{$\begin{array}{l}\text { Odd ratio } \\
0.053\end{array}$} & \multirow{2}{*}{$\begin{array}{l}\text { Std err } \\
0.005\end{array}$} & \multirow{2}{*}{$\begin{array}{l}z \\
-29.6\end{array}$} & \multirow{2}{*}{$\begin{array}{l}p>\mathrm{z} \\
0.000\end{array}$} & \multicolumn{2}{|c|}{$\begin{array}{l}\text { [95\% Conf. } \\
\text { interval] }\end{array}$} \\
\hline & & & & & & & 0.044 & 0.064 \\
\hline Gender & & Female & 0.913 & 0.029 & -2.88 & 0.004 & 0.858 & 0.971 \\
\hline \multirow[t]{4}{*}{ Age } & $\mathrm{X}_{2}$ & $40-45$ & 0.899 & 0.041 & -2.35 & 0.019 & 0.822 & 0.983 \\
\hline & $X_{3}$ & $46-52$ & 0.824 & 0.039 & -4.06 & 0.000 & 0.751 & 0.905 \\
\hline & $\mathrm{X}_{4}$ & $53-60$ & 0.698 & 0.037 & -6.78 & 0.000 & 0.629 & 0.775 \\
\hline & $\mathrm{X}_{5}$ & Over 60 & 0.526 & 0.035 & -9.62 & 0.000 & 0.461 & 0.599 \\
\hline \multirow[t]{2}{*}{ Academic rank } & $\mathrm{X}_{6}$ & Associate prof & 1.175 & 0.045 & 4.2 & 0.000 & 1.090 & 1.268 \\
\hline & $\mathrm{X}_{7}$ & Full prof & 1.387 & 0.067 & 6.76 & 0.000 & 1.262 & 1.526 \\
\hline \multirow[t]{2}{*}{ Scientific activity } & $\mathrm{X}_{8}$ & Highly diversified & 1.312 & 0.044 & 8.15 & 0.000 & 1.229 & 1.401 \\
\hline & $\mathrm{X}_{9}$ & Highly specialized & 0.728 & 0.029 & -7.98 & 0.000 & 0.673 & 0.787 \\
\hline Past behaviour & $\mathrm{X}_{10}$ & Previous collab & 3.965 & 0.156 & 34.94 & 0.000 & 3.670 & 4.284 \\
\hline \multirow[t]{3}{*}{ Research performance } & $X_{11}$ & Tot. publications & 1.012 & 0.001 & 17.05 & 0.000 & 1.010 & 1.013 \\
\hline & $\mathrm{X}_{12}$ & FSS & 1.055 & 0.016 & 3.59 & 0.000 & 1.025 & 1.087 \\
\hline & $X_{13}$ & Top 20\% & 1.228 & 0.056 & 4.52 & 0.000 & 1.123 & 1.342 \\
\hline Environment & $\mathrm{X}_{14}$ & Peers collaborating & 2.714 & 0.101 & 26.94 & 0.000 & 2.524 & 2.918 \\
\hline \multirow[t]{2}{*}{ University type } & $\mathrm{X}_{15}$ & Private & 0.785 & 0.066 & -2.88 & 0.004 & 0.666 & 0.925 \\
\hline & $\mathrm{X}_{16}$ & Polytechnic or SS & 1.146 & 0.072 & 2.17 & 0.030 & 1.013 & 1.296 \\
\hline \multirow[t]{2}{*}{ University size } & $\mathrm{X}_{17}$ & Medium & 0.870 & 0.050 & -2.4 & 0.016 & 0.776 & 0.975 \\
\hline & $\mathrm{X}_{18}$ & Large & 0.725 & 0.041 & -5.65 & 0.000 & 0.649 & 0.811 \\
\hline \multirow[t]{4}{*}{ University location } & $\mathrm{X}_{19}$ & South & 1.242 & 0.069 & 3.91 & 0.000 & 1.114 & 1.384 \\
\hline & $X_{20}$ & Center & 1.350 & 0.072 & 5.65 & 0.000 & 1.216 & 1.498 \\
\hline & $\mathrm{X}_{21}$ & Northeast & 1.393 & 0.076 & 6.05 & 0.000 & 1.251 & 1.551 \\
\hline & $\mathrm{X}_{22}$ & Northwest & 1.482 & 0.082 & 7.15 & 0.000 & 1.331 & 1.652 \\
\hline
\end{tabular}

Logit regression, dependent variable: 1 in case of publications in co-authorship with industry; 0, otherwise Number of obs. $=32,792$

LR $\operatorname{chi} 2(28)=6158.1 ;$ Prob $>$ chi $2=0.0000$

Log likelihood $=-16,010.5$; Pseudo $\mathrm{R}^{2}=0.1613$

data in column 4 Table 5 confirm the indication of the correlation analysis, on the fact that the main driver of an academic's public-private research collaboration is their track record $\left(\mathrm{X}_{10}\right)$.

A particularly interesting result concerns the effect of research performance: net of what can be considered an exposure variable (the number of total publications), the OR of the Top 20\% variable (1.228) indicates that a standing in the top performance quintile increases the probability of engaging with industry by $23 \%$. Contrarily, the coefficient relative to FSS is quite low (1.055), although positive and statistically significant.

The contextual characteristics all show significant effects under equal conditions. Among them, the most important driver is the presence of other colleagues from the same field, actively collaborating with companies (odds ratio 2.714). The coefficients of both research staff variables considered $(0.870$ and 0.725$)$ are significant and well below one, indicating an inverse relation between propensity to co-publication with industry and university size. Finally, the coefficients of the four dummies related to location indicate an increase in the propensity to collaborate from south to north. 


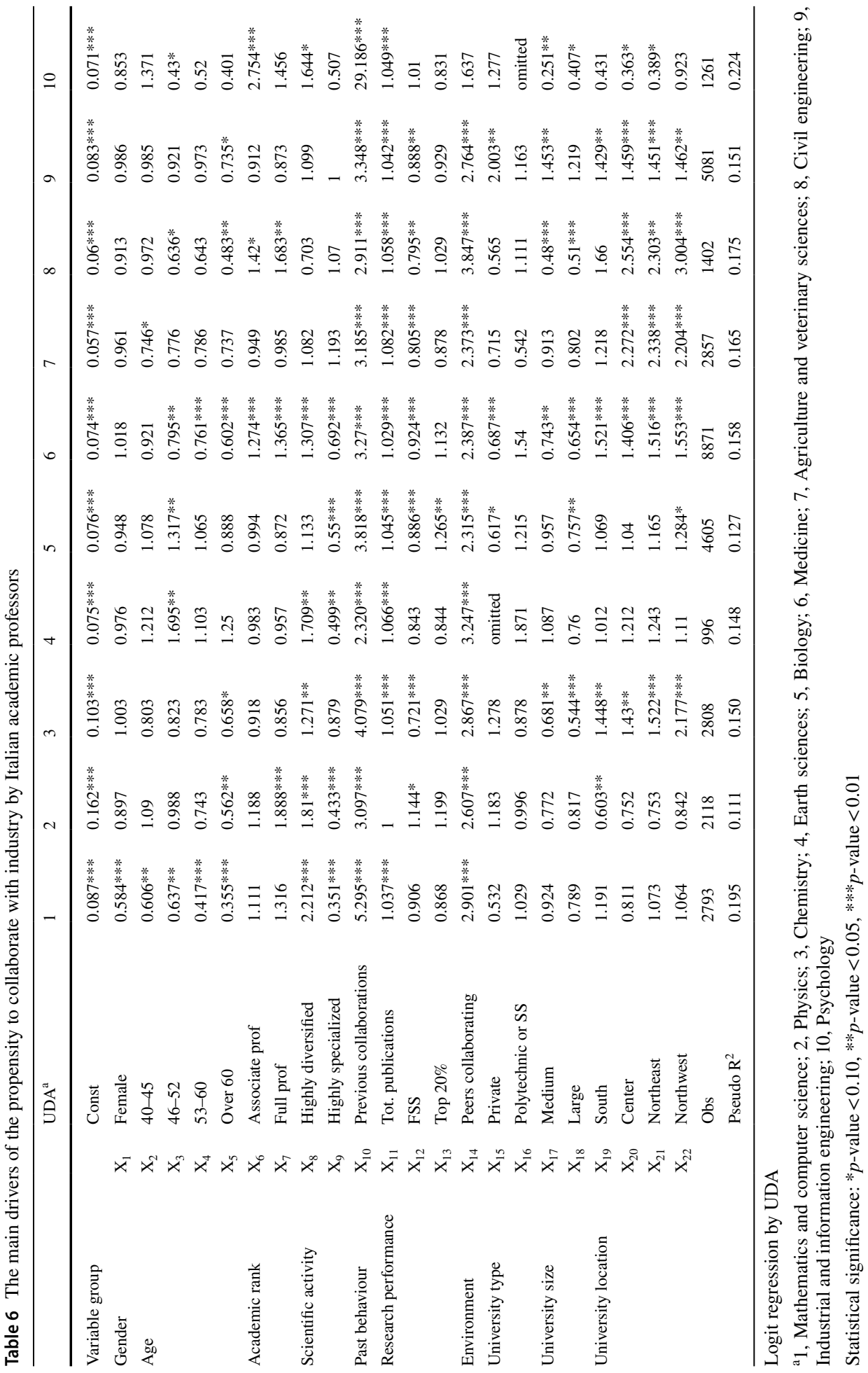


The analysis was repeated for each UDA for purposes of detecting the importance of individual and contextual drivers across disciplines. Table 6 reports the results of the logit regression on the professors of each discipline. Although reducing the number of observations brings loss of significance for many coefficients, it remains evident that there is strong heterogeneity among the disciplines. Medicine (UDA 6), the area with the most observations (over 8800), then also has the highest number of significant coefficients, whose values confirm the effects of covariates detected at overall level. Gender and age seem to lose consequence, except in Mathematics and computer science (UDA 1), where the effect of these personal traits seems even more pronounced than at overall level. In this same UDA, the odds ratio for 'highly diversified' scientific activity (2.212) is very high, vs very low for the opposite character (highly specialized, 0.351). Although less pronounced than in UDA 1, this pair of variables shows the same type of effect in all other UDAs except 7, 8, 9.

Among individual traits, 'Previous collaborations' remains the driver with the greatest weight, always significant, with minimum odds ratio in UDA 4 (Earth sciences, 2.320). Productivity (FSS) shows significant impact in all areas but Mathematics, Earth sciences, and Psychology (respectively UDAs 1, 4, 10), but of opposite sign to that seen at the overall level (i.e. odds ratios always lower than one), with the sole exception of Physics (1.144).

Concerning the contextual effect of university size, the coefficients confirm, at least at sign level, what is observed at overall level. An exception is UDA 9 (Industrial and information engineering), where the marginal effect of size is positive, especially comparing between 'small' and 'medium' research faculties. The effect of the geographic localization variable seems heterogeneous and does not always confirm the primacy of the northwest among the different areas. In Mathematics and computer science no effect is detectable. Two other UDAs (Physics, Psychology) seem to present the rare case of the Italian islands offering greater opportunities for academic-industrial interaction than the rest of the country.

\subsection{Gender effects: the interaction with age and academic career stage}

As seen above, gender, age and academic rank have a significant effect on the propensity of an academic to collaborate with private companies. These are direct effects, but it may be interesting to explore the mediating effects that age and academic career stages may have on the lower collaboration propensity of women compared to men. In particular, the propensity of women to collaborate may vary more than that of men over the course of their professional life, due to the greater interference of family responsibilities and the fact that women tend to be tied up in more university administrative tasks and teaching, especially in the early stages of their career.

To this end, we re-run the above described logit regression by adding to the 22 independent variables, four interaction effects, two related to gender and age, and two to gender and academic rank, as specified by the following dummies:

- $\mathrm{I}_{1}, 1$ for female professors 45 or less aged; 0 , otherwise;

- $\mathrm{I}_{2}, 1$ for female professors over 60 aged; 0, otherwise;

- $\mathrm{I}_{3}, 1$ for female associate professors; 0, otherwise;

- $\mathrm{I}_{4}, 1$ for female full professors; 0 , otherwise; 
Table 7 Direct and interaction effects of gender with age and academic career stage on the propensity to collaborate with industry by Italian academic professors

\begin{tabular}{lllllllll}
\hline Variable group & Value & & Odd ratio & Std err & $\mathrm{z}$ & $p>\mathrm{z}$ & $\begin{array}{l}\text { [95\% Conf. } \\
\text { interval] }\end{array}$ \\
\hline Gender & & & & & & & & \\
Age & Female & $\mathrm{X}_{1}$ & 0.939 & 0.059 & -1.00 & 0.318 & 0.830 & 1.062 \\
& $40-45$ & $\mathrm{X}_{2}$ & 0.892 & 0.041 & -2.51 & 0.012 & 0.816 & 0.975 \\
& $46-52$ & $\mathrm{X}_{3}$ & 0.807 & 0.045 & -3.88 & 0.000 & 0.724 & 0.900 \\
& $53-60$ & $\mathrm{X}_{4}$ & 0.683 & 0.041 & -6.35 & 0.000 & 0.607 & 0.768 \\
Interaction age versus & Young $(<45)$ female & $\mathrm{I}_{1}$ & 0.977 & 0.071 & -0.33 & 0.744 & 0.848 & 1.125 \\
gender & Old (>60) female & $\mathrm{I}_{2}$ & 1.120 & 0.135 & 0.94 & 0.347 & 0.884 & 1.418 \\
Academic rank & Associate prof & $\mathrm{X}_{6}$ & 1.202 & 0.057 & 3.90 & 0.000 & 1.096 & 1.319 \\
& Full prof & $\mathrm{X}_{7}$ & 1.438 & 0.080 & 6.49 & 0.000 & 1.289 & 1.604 \\
Interaction rank versus & Female Associate prof & $\mathrm{I}_{3}$ & 0.954 & 0.074 & -0.61 & 0.544 & 0.819 & 1.111 \\
gender & Female Full prof & $\mathrm{I}_{4}$ & 0.887 & 0.094 & -1.14 & 0.255 & 0.721 & 1.091 \\
\hline
\end{tabular}

Number of obs. $=32,792$

LR chi2 $(28)=6139.5 ;$ Prob $>$ chi $2=0.0000$

Log likelihood $=-16,019.8 ;$ Pseudo $\mathrm{R}^{2}=0.1608$

Results are reported in Table 7. For ease of reading, the odd ratios and statistics for all the other covariates are not shown; in any case, they do not vary substantially from what is shown in Table 5. In particular, the direct effects are all confirmed, at least in sign. The odd ratio of the gender variable (0.939) confirms the lower propensity of women compared to men, however the coefficient loses its significance ( $p$-value 0.318 ). On the other hand, both the sign and the significance of the direct effects of age and academic rank remain unchanged. The interaction effects all show high p-values but the absolute values of the odd ratios indicate possible interesting effects: the lower propensity to collaborate with industry is typical of younger women $\left(\mathrm{I}_{1}=0.977\right)$ compared to their older colleagues $\left(\mathrm{I}_{2}=1.120\right)$. Results concerning the interaction of gender with academic rank are also interesting: the gap in the propensity to collaborate with industry tends to widen for women as they progress in their academic careers $\left(I_{3}=0.954 ; I_{4}=0.887\right)$. However, it should be noted that these effects are not statistically significant.

\subsection{The effects of the research structure of the territory}

Among the contextual covariates with significant effects on the propensity of a professor to collaborate with industry, the university location certainly deserves a closer examination: it is in fact possible to empirically profile the characteristics of a territory in terms of human resources and business demographics. In particular, in the presence of a possible 'geographical proximity effect', we can hypothesise that the probability for a professor to be engaged in a scientific collaboration with a private company increases with the overall size of private research staff in the territory where his/her university is located, as well as 
Table 8 NUTS2 level data of private R\&S staff (FTE) and patenting intensity, in Italian regions Source ISTAT $^{12}$

\begin{tabular}{|c|c|c|c|c|c|}
\hline \multirow[b]{2}{*}{ Macro-area } & \multirow[b]{2}{*}{ Region } & \multicolumn{2}{|c|}{$\begin{array}{l}\text { Total R\&D staff (FTE) } \\
\text { in private companies }\end{array}$} & \multicolumn{2}{|c|}{ Patenting intensity } \\
\hline & & Avg 2008-2012 & Level & Avg 2008-2012 & Level \\
\hline \multirow[t]{4}{*}{ Northwest } & Liguria & 3292 & Mid & 72.5 & Mid \\
\hline & Lombardia & 29,236 & High & 126.2 & High \\
\hline & Piemonte & 16,458 & High & 112.2 & High \\
\hline & Valle d'Aosta & 213 & Low & 52.3 & Mid \\
\hline \multirow[t]{4}{*}{ Northeast } & Emilia Romagna & 14,535 & High & 154.2 & High \\
\hline & Friuli Venezia Giulia & 3224 & Mid & 172.3 & High \\
\hline & Trentino Alto Adige & 2515 & Mid & 95.7 & High \\
\hline & Veneto & 14,928 & High & 113.7 & High \\
\hline \multirow[t]{4}{*}{ Center } & Lazio & 9002 & High & 35.2 & Mid \\
\hline & Marche & 2595 & Mid & 78.6 & Mid \\
\hline & Toscana & 5437 & High & 79.4 & Mid \\
\hline & Umbria & 808 & Low & 38.1 & Mid \\
\hline \multirow[t]{6}{*}{ South } & Abruzzo & 1230 & Low & 32.1 & Mid \\
\hline & Basilicata & 211 & Low & 11.1 & Low \\
\hline & Calabria & 188 & Low & 6.2 & Low \\
\hline & Campania & 4564 & Mid & 13.4 & Low \\
\hline & Molise & 86 & Low & 4.9 & Low \\
\hline & Puglia & 1532 & Mid & 13.7 & Low \\
\hline \multirow[t]{2}{*}{ Islands } & Sardegna & 296 & Low & 10.4 & Low \\
\hline & Sicilia & 1904 & Mid & 8.0 & Low \\
\hline
\end{tabular}

(size being equal) with the innovation rate of companies in the territory. To this end, two variables were considered:

- The R\&D staff (FTE) in private companies, at NUTS2 $2^{11}$ level,

- The patenting intensity of the region, given by the number of patents filed at the EPO (European patent office) by organisations in the territory, per million inhabitants of the territory.

The data were extracted from the 'Territorial Indicators for Development Policies' report of the Italian Institute of Statistics (ISTAT) ${ }^{12}$ and are shown in Table 8.

\footnotetext{
${ }^{11}$ The NUTS classification (Nomenclature of territorial units for statistics) is a hierarchical system for dividing up the economic territory of the EU and the UK for the purpose of:

- The collection, development and harmonisation of European regional statistics.

- Socio-economic analyses of the regions.

- NUTS 1: major socio-economic regions.

- NUTS 2: basic regions for the application of regional policies.

- NUTS 3: small regions for specific diagnoses.

12 https://www.istat.it/it/archivio/16777, last accessed on 8 September 2021.
} 
Table 9 Contextual covariates: effects of the research structure of the territory on the propensity to collaborate with industry by Italian professors

\begin{tabular}{lllllllll}
\hline Variable group & & Value & Odd ratio & Std err & $\mathrm{z}$ & $p>\mathrm{z}$ & $\begin{array}{l}{[95 \% \text { Conf. }} \\
\text { interval] }\end{array}$ \\
\hline Environment & & & & & & & & \\
University type & $\mathrm{X}_{14}$ & Peers collaborating & 2.715 & 0.101 & 26.95 & 0.000 & 2.525 & 2.920 \\
& $\mathrm{X}_{15}$ & Private & 0.788 & 0.065 & -2.88 & 0.004 & 0.670 & 0.927 \\
& $\mathrm{X}_{16}$ & Polytechnic or SS & 1.170 & 0.070 & 2.62 & 0.009 & 1.040 & 1.316 \\
University size & $\mathrm{X}_{17}$ & Medium & 0.852 & 0.049 & -2.78 & 0.005 & 0.761 & 0.954 \\
& $\mathrm{X}_{18}$ & Large & 0.710 & 0.041 & -6.01 & 0.000 & 0.634 & 0.794 \\
Total R\&D staff in private & $\mathrm{X}_{23}$ & Mid & 1.094 & 0.057 & 1.73 & 0.083 & 0.988 & 1.211 \\
companies of the region & $\mathrm{X}_{24}$ & High & 1.079 & 0.067 & 1.23 & 0.219 & 0.956 & 1.218 \\
Patenting intensity in the & $\mathrm{X}_{25}$ & Mid & 1.175 & 0.058 & 3.26 & 0.001 & 1.066 & 1.294 \\
region & $\mathrm{X}_{26}$ & High & 1.268 & 0.070 & 4.27 & 0.000 & 1.137 & 1.414 \\
\hline
\end{tabular}

Number of obs. $=32,792$

LR $\operatorname{chi} 2(28)=6130.5 ;$ Prob $>\operatorname{chi} 2=0.0000$

Log likelihood $=-16,024.3$; Pseudo $\mathrm{R}^{2}=0.1606$

For the purposes of the work, the general logit regression was repeated by replacing the 4 covariates related to university location $\left(\mathrm{X}_{19}-\mathrm{X}_{22}\right)$ with as many dummies $\left(\mathrm{X}_{23}-\mathrm{X}_{26}\right)$ specified in following way. For each of the two ISTAT indicators, the distribution of values was divided into 3 classes (Low, Mid, High) and the relevant variables specified by means of 2 dummies (baseline 'Low'). The results are shown in Table 9: to simplify the reading, the statistics of the 'individual covariates' $\left(\mathrm{X}_{1}-\mathrm{X}_{13}\right)$ have been omitted.

The substitution of variables does not alter the value of the odd ratios of the other contextual covariates $\left(\mathrm{X}_{14}-\mathrm{X}_{18}\right)$. Rather, of the two new variables, the first one (total $\mathrm{R} \& \mathrm{D}$ staff in private companies of the region) shows positive but limited effects, and with $p$-values above 0.05. Instead, the second variable (patenting intensity in the region) shows positive, statistically significant and increasing effects. All other things being equal, an academic from a university located in a region with medium patenting intensity shows a $17.5 \%$ higher propensity to collaborate with private companies than a colleague operating in a region with low patenting intensity. This increase rises to $+26.8 \%$ when comparing academics operating in low and high patenting intensity regions respectively.

\section{Discussion and conclusions}

Over the past four decades, governments, industry, and funding organizations have increasingly pressured universities to contribute to national innovation processes and to become more 'entrepreneurial' (Etzkowitz, 1983; Todorovic et al., 2011). Alongside their more traditional functions of research and teaching, they are now expected to fulfill the so-called 'third mission' (Etzkowitz \& Leydesdorff, 1995). One of the means for universities to pursue this new mission is to engage in research collaboration with industry. The potentials of this strategy have gained increasing attention among scholars and action on the part of policy-makers in the form of incentivizing initiatives (Davenport et al., 1998; Debackere \& Veugelers, 2005). 
From the universities' viewpoint, the economic incentives embedded in industry collaboration (e.g. access to financial resources, complementary material assets) are not always enough to support the engagement desired. Countering the attractions are disincentives, in particular transactions costs (Belkhodja \& Landry, 2007; Drejer \& Jørgensen, 2005), which will clearly vary with the level of heterogeneity among members of the academic-industry research team (Abramo et al., 2011).

Furthermore, the implementation of national performance-based research funding systems can in fact negatively affect the policies incentivizing public-private collaborations. It is known that academics' collaboration with colleagues in the private sector leads to publications with average impact lower than those stemming from intra-sector collaborations, and to a lower proportion of highly-cited publications. The same holds true when foreign co-authors are involved (Abramo et al., 2021). From the perspective of the public scientist, increasingly subject to assessments based on the scholarly impact of their scientific activity, this awareness might act as a deterrent. This leads to counter-purposes, or at least trade-offs, between policies aimed at increasing public researcher productivity and others aimed at encouraging involvement in industrial research collaborations. For all these reasons, policy-makers, industry and the university managers would clearly benefit from understanding the main drivers of academic engagement in collaboration with industry, especially in such countries as Italy where the current levels of collaboration are suboptimal. With better knowledge of individual and contextual features, incentive systems can be better formulated and targeted. For just and effective operation, the relevant variables should also be taken into account in performance measurements and reward systems. Considering only one example: to demand that the academics of Engineering and Mathematics, or those of northern vs southern Italy, all achieve the same propensity of industrial research collaboration would be unfair, as well as dysfunctional. The empirical results of the current study, in fact, illustrate the varying cross-sector collaboration propensities of research fields, aligning with findings by Tijssen (2012) and Cohen et al. (2020). Considering the potentials of Italian policy in particular, they show the outstanding effect of territorial location on academics, reflecting the disproportionate concentration of industry in the north vs south and islands. Thus, policies and management practices that account for field differences are likely to be more effective than those that do not (Azoulay et al., 2007; Fabrizio \& Minin, 2008).

Other relevant results of the analysis are that female scientists show $8.7 \%$ lower propensity than male to collaborate with industry. This data confirms the indications of previous studies on the subject, in particular Weerasinghe and Dedunu (2020), Tartari and Salter (2015) and Calvo et al. (2019). The last authors found that 'research groups led by men have around $10 \%$ higher probability of showing interest in R\&D co-operation with firms', a datum absolutely similar to that obtained here despite obvious methodological differences.

Age seems to have a systematically negative impact on the propensity to collaborate. In particular, compared to an under-40 professor, the probability of an over-60 collaborating in joint publication with companies is practically halved. This further confirms D'Este and Patel (2007): 'the sign on the age variable is negative and the impact is significant [...] suggesting that the younger the researcher the higher the probability of engaging in a greater variety of interactions, and also of engaging more frequently across a wider range of interactions'. In contrast, Weerasinghe and Dedunu (2020) report that impact of age is non-linear, but this result may have been influenced by the particularly small sample size (178 academics of Sri Lankan state universities).

Academic rank shows a positive effect on the propensity for research collaboration with industry: full and associate professors show a higher probability compared to assistant 
professors, respectively by $39 \%$ and $18 \%$, confirming the summary conclusion of Perkmann et al. (2013), who refer to a large number of previous works reporting a positive effect of professorial tenure on collaboration activities with industry.

Results also show that, all others equal, the gender gap to collaborate is higher for young professors, and at the late stages of academic career.

Different explanations come to mind, with implications for academic policy, social policy, and management. Women could be more resistant to territorial movement for reasons of simultaneous involvement in other roles, particularly in family. Throughout the world, there remains a cultural heritage in which industry (in particular manufacturing, with which Engineering academics tend to collaborate most) is seen as mainly for men (EU, 2017; Abramo et al., 2013b).

Regarding the level of research specialization/diversification, an academic professor with a highly diversified scientific profile shows a $31.2 \%$ higher probability of collaborating with companies than an 'intermediate' profile. Conversely, a highly specialized profile has a 27.2 percent lower probability of collaborating with companies. In this case, there is no benchmark in the literature to report this result, therefore constituting an effective advancement of knowledge on the subject.

Counterintuitively, leaving aside top 20 percent performers, research productivity has a weak effect on the propensity to engage in cross-sector collaborations. The result is in line with Abramo et al. (2011), who interpret it in the light of inefficiency in selection of academic collaborators by industry, due to the evident information asymmetry on the demand/ supply sides of new knowledge. Blumenthal et al. (1996) likewise failed to find any clear relationship between academic productivity and cross-sector collaboration activities.

The main driver of an academic's public-private research collaboration is their track record. Compared to professors without, those with a previous collaboration have $300 \%$ greater probability of continuing. The data confirms the conclusions of D'Este and Patel (2007) that 'those researchers with a record of past interaction are more likely to be involved [...] with industry.' Apart from past experience, the presence of colleagues from the same field, actively collaborating with companies, is the most important contextual driver for an academic, confirming the indication of Tartari et al. (2014).

In Italy, the public character of the university also matters. In private universities, all other things being equal, the propensity to collaborate is lower (odds ratio 0.785). We have found no studies on the subject in the literature to compare our findings with. Professors of polytechnics and SSs show a higher propensity (+14.6\%) compared to those of generalist universities. Again, comparison with prior knowledge is unavailable, except for a similar result achieved by D'Este and Patel (2007) in the UK, but referring only to institutions formerly tagged as polytechnics (i.e. higher education institutions, upgraded to university status in 1992). On the other hand, such results are no surprise, considering that research groups concentrated on the technical sciences are more likely to attract industry attention.

Furthermore, as the university size increases, the propensity to co-publication with industry decreases. The results seem new with respect to knowledge on the subject. Schartinger et al. (2001) had expected a U-shaped curve of size effects on interactions, while for D'Este and Patel (2007) departmental variables (including the size of the relative research staff) 'lose their significance once individual characteristics are introduced.'

Finally, confirming the state of the art on the subject, location also matters: The propensity to collaborate increases with latitude (i.e. towards industrial territories of northern Italy). Compared to academic professors working in the two island regions (Sicily and Sardinia), all other things being equal, those of the south show a propensity greater by $24.2 \%$; those of the center, $35 \%$; those of the northeast, $39.3 \%$; and finally, those of the northwest, 
48.2\%. This pattern confirms that for university professors, interaction with companies depends on the territorial level of concentration of industrial activities in general and, in particular, of knowledge-intensive industry. In a nutshell, all other factors being equal, it is the professor under age 40 who engages most in research collaboration with industry; it is the male, the full professor, the top performer, the one with highly diversified research, and who has a certain tradition in collaborating with industry. This professor is likely to be part of a staff used to collaborating with industry, in a small university, typically a polytechnic or a school for advanced studies. All of this presents a profile very similar to that extrapolated by Perkmann et al. (2021), in their recent review of the literature on the theme.

The findings of empirical investigations such as ours can be generalized to other countries with extreme caution. For some results in particular, comparability to any other countries would require similarity in the contextual variables: cultural, social, industrial, and of the research systems themselves.

Moreover, the intrinsic limits of all analyses adopting bibliometric techniques require caution. First of all, the circumstances that not all universities-industry research collaborations lead to results encodable in scientific publications, and not all university/industry co-authored publications are the outcome of real research collaborations. Co-authorship of a paper represents the successful outcome of a collaboration, rather than the collaboration per se. Also, the bibliographic repertories (such as WoS, used here) do not register all publications. Furthermore, the measurement of research performance by citation-based indicators (FSS) is subject to a number of limits and assumptions. Finally, citations can also be negative or inappropriate, and in any case they certify only scholarly impact, forgoing other types of impact. These limitations should always be recalled when interpreting findings arising from bibliometric techniques.

The current study has approached the issue of academic-industry collaboration from the view of the academics. It would be equally interesting to investigate from the industry perspective, concerning the drivers of engaging in private-public collaboration.

Author contributions GA: Conceptualization, Methodology, Validation, Investigation, Writing-Original Draft, Supervision. CAD: Methodology, Software, Validation, Formal analysis, Investigation, Data Curation, Writing - Original Draft.

Funding Open access funding provided by Università degli Studi di Roma Tor Vergata within the CRUICARE Agreement. This research was partly funded by the Italian Ministry of Universities and Research, PRIN 2017NKWYFC 'The effects of evaluation on academic research: knowledge production and methodological issues'.

Data availability Data are available on request.

Code availability Not applicable.

\section{Declarations}

Conflict of interest The authors declare that they have no known competing financial interests or personal relationships that could have appeared to influence the work reported in this paper.

Ethical approval This article does not contain any studies with human participants or animals performed by any of the authors. 
Open Access This article is licensed under a Creative Commons Attribution 4.0 International License, which permits use, sharing, adaptation, distribution and reproduction in any medium or format, as long as you give appropriate credit to the original author(s) and the source, provide a link to the Creative Commons licence, and indicate if changes were made. The images or other third party material in this article are included in the article's Creative Commons licence, unless indicated otherwise in a credit line to the material. If material is not included in the article's Creative Commons licence and your intended use is not permitted by statutory regulation or exceeds the permitted use, you will need to obtain permission directly from the copyright holder. To view a copy of this licence, visit http://creativecommons.org/licenses/by/4.0/.

\section{References}

Abramo, G., D’Angelo, C.A., Di Costa, F., \& Solazzi, M. (2011). The role of information asymmetry in the market for university-industry research collaboration. The Journal of Technology Transfer, 36(1), 84-100. https://doi.org/10.1007/s10961-009-9131-5

Abramo, G., D’Angelo, C. A., \& Murgia, G. (2013a). The collaboration behaviors of scientists in Italy: A field level analysis. Journal of Informetrics, 7(2), 442-454. https://doi.org/10.1016/j.joi.2013.01.009

Abramo, G., D’Angelo, C.A., \& Murgia, G. (2013b). Gender differences in research collaboration. Journal of Informetrics, 7(4), 811-822. https://doi.org/10.1016/j.joi.2013.07.002

Abramo, G., \& D'Angelo, C.A. (2014). How do you define and measure research productivity? Scientometrics, 101(2), 1129-1144. https://doi.org/10.1007/s11192-014-1269-8

Abramo, G., D’Angelo, C.A., \& Murgia, G. (2014). Variation in research collaboration patterns across academic ranks. Scientometrics, 98(3), 2275-2294. https://doi.org/10.1007/s11192-013-1185-3

Abramo, G., D’Angelo, C.A., \& Murgia, G. (2017). The relationship among research productivity, research collaboration, and their determinants. Journal of Informetrics, 11(4), 1016-1030. https://doi.org/10. 1016/j.joi.2017.09.007

Abramo, G., D'Angelo, C.A., \& Di Costa, F. (2021). The scholarly impact of private sector research a multivariate analysis. Journal of Informetrics, 15(3), 101191. https://doi.org/10.1016/j.joi.2021.101191

Azoulay, P., Ding, W. W., \& Stuart, T. E. (2007). The determinants of faculty patenting behavior: Demographics or opportunities? Journal of Economic Behavior and Organization, 63, 599-623.

Balconi, M., \& Laboranti, A. (2006). University-industry interactions in applied research: The case of microelectronics. Research Policy, 35(10), 1616-1630. https://doi.org/10.1016/j.respol.2006.09.018

Bayer, A. E., \& Smart, J. C. (1991). Career publication patterns and collaborative 'styles' in American academic science. Journal of Higher Education, 62(6), 613-636.

Bekkers, R., \& Bodas Freitas, I. M. (2008). Analysing knowledge transfer channels between universities and industry: To what degree do sectors also matter? Research Policy, 37(10), 1837-1853. https://doi.org/ 10.1016/j.respol.2008.07.007

Belkhodja, O., \& Landry, R. (2007). The Triple-Helix collaboration: Why do researchers collaborate with industry and the government? What are the factors that influence the perceived barriers? Scientometrics, 70, 301-332. https://doi.org/10.1007/s11192-007-0205-6

Berbegal-Mirabent, J., Sánchez García, J. L., \& Ribeiro-Soriano, D. E. (2015). University-industry partnerships for the provision of R\&D services. Journal of Business Research, 68(7), 1407-1413. https://doi. org/10.1016/j.jbusres.2015.01.023

Bercovitz, J., \& Feldman, M. (2003). Technology transfer and the academic department: who participates and why? In: Paper presented at the DRUID summer conference 2003, Copenhagen, June 12-14.

Blumenthal, D., Campbell, E. G., Causino, N., \& Louis, K. S. (1996). Participation of life science faculty in research relationships with industry. New England Journal of Medicine, 335(23), 17341739. https://doi.org/10.1056/NEJM199612053352305

Boschini, A., \& Sjögren, A. (2007). Is team formation gender neutral? Evidence from coauthorship patterns. Journal of Labor Economics, 25(2), 325-365. https://doi.org/10.1086/510764

Bowyer, K., Kranenburg, C., \& Dougherty, S. (2001). Edge detector evaluation using empirical ROC curves. Computer Vision and Image Understanding, 84(1), 77-103.

Bozeman, B., \& Corley, E. (2004). Scientists' collaboration strategies: Implications for scientific and technical human capital. Research Policy, 33(4), 599-616. https://doi.org/10.1016/j.respol.2004.01. 008

Bozeman, B., \& Gaughan, M. (2011). How do men and women differ in research collaborations? An analysis of the collaborative motives and strategies of academic researchers. Research Policy, 40(10), 1393-1402. https://doi.org/10.1016/j.respol.2011.07.002 
Calvo, N., Fernández-López, S., \& Rodeiro-Pazos, D. (2019). Is university-industry collaboration biased by sex criteria? Knowledge Management Research and Practice, 17(4), 408-420. https://doi.org/10. 1080/14778238.2018.1557024

Cohen, W. M., Nelson, R. R., \& Walsh, J. P. (2002). Links and impacts: The influence of public research on industrial R\&D. Management Science, 48(1), 1-23.

Cohen, W. M., Sauermann, H., \& Stephan, P. (2020). Not in the job description: The commercial activities of academic scientists and engineers. Management Science, 66(9), 4108-4117.

D’Angelo, C.A., Giuffrida, C., \& Abramo, G. (2011). A heuristic approach to author name disambiguation in bibliometrics databases for large-scale research assessments. Journal of the American Society for Information Science and Technology, 62(2), 257-269. https://doi.org/10.1002/asi.21460

D'Este, P., \& Patel, P. (2007). University-industry linkages in the UK: What are the factors underlying the variety of interactions with industry? Research Policy, 36(9), 1295-1313. https://doi.org/10. 1016/j.respol.2007.05.002

D'Este, P., \& Perkmann, M. (2011). Why do academics engage with industry? The entrepreneurial university and individual motivations. The Journal of Technology Transfer, 36(3), 316-339.

Davenport, S., Davies, J., \& Grimes, C. (1998). Collaborative research programmes: Building trust from difference. Technovation, 19(1), 31-40. https://doi.org/10.1016/S0166-4972(98)00083-2

Debackere, K., \& Veugelers, R. (2005). The role of academic technology transfer organizations in improving industry science links. Research Policy, 34(3), 321-342. https://doi.org/10.1016/j.respol. 2004.12.003

Di Gregorio, D., \& Shane, S. (2003). Why do some universities generate more start-ups than others? Research Policy, 32(2), 209-227.

Drejer, I., \& Jørgensen, B. H. (2005). The dynamic creation of knowledge: Analysing public-private collaborations. Technovation, 25(2), 83-94. https://doi.org/10.1016/S0166-4972(03)00075-0

Etzkowitz, H. (1983). Entrepreneurial scientists and entrepreneurial universities in American academic science. Minerva, 21(2-3), 198-233. https://doi.org/10.1007/BF01097964

Etzkowitz, H., \& Leydesdorff, L. (1995). The Triple Helix: University-industry—government relations a laboratory for knowledge based economic development. EASST Review, 14, 14-19.

EU. (2017). Special Eurobarometer 465: Gender Equality 2017. EU Open Data Portal, https://data. europa.eu/euodp/en/data/dataset/S2154_87_4_465_ENG, last accessed on 8 September 2021.

Fabrizio, K., \& Minin, A. (2008). Commercializing the laboratory: Faculty patenting and the open science environment. Research Policy, 37(5), 914-931.

Fan, X., Yang, X., \& Chen, L. (2015). Diversified resources and academic influence: Patterns of university-industry collaboration in Chinese research-oriented universities. Scientometrics, 104(2), 489-509. https://doi.org/10.1007/s11192-015-1618-2

Garcia, R., Araújo, V., Mascarini, S., Santos, E. G., \& Costa, A. R. (2020). How long-term universityindustry collaboration shapes the academic productivity of research groups. Innovation: Organization and Management, 22(1), 56-70. https://doi.org/10.1080/14479338.2019.1632711

Giuri, P., Munari, F., Scandura, A., \& Toschi, L. (2019). The strategic orientation of universities in knowledge transfer activities. Technological Forecasting and Social Change, 138, 261-278. https:// doi.org/10.1016/j.techfore.2018.09.030

Guimón, J., \& Paunov, C. (2019). Science-industry knowledge exchange: A mapping of policy instruments and their interactions. OECD Science, Technology and Industry Policy Papers, No. 66, OECD Publishing, Paris, DOI: https://doi.org/10.1787/66a3bd38-en, last accessed on 8 September 2021.

He, Z., Geng, X., \& Campbell-Hunt, C. (2009). Research collaboration and research output: A longitudinal study of 65 biomedical scientists in a New Zealand university. Research Policy, 38(2), 306-317. https://doi.org/10.1016/j.respol.2008.11.011

Huang, M.-H., Yang, H.-W., \& Chen, D.-Z. (2015). Industry-academia collaboration in fuel cells: A perspective from paper and patent analysis. Scientometrics, 105(2), 1301-1318. https://doi.org/10.1007/ s11192-015-1748-6

Iorio, R., Labory, S., \& Rentocchini, F. (2016). The importance of pro-social behaviour for the breadth and depth of knowledge transfer activities: An analysis of italian academic scientists. Research Policy, 46(2), 497-509. https://doi.org/10.1016/j.respol.2016.12.003

Katz, J. S., \& Martin, B. R. (1997). What is research collaboration? Research Policy, 26(1), 1-18. https:// doi.org/10.1016/S0048-7333(96)00917-1

Lee, S., \& Bozeman, B. (2005). The impact of research collaboration on scientific productivity. Social Studies of Science, 35(5), 673-702. https://doi.org/10.1177/0306312705052359

Lim, K. (2004). The relationship between research and innovation in the semiconductor and pharmaceutical industries (1981-1997). Research Policy, 33(2), 287-321. 
Llopis, O., Sánchez-Barrioluengo, M., Olmos-Peñuela, J., \& Castro-Martínez, E. (2018). Scientists' engagement in knowledge transfer and exchange: Individual factors, variety of mechanisms and users. Science and Public Policy, 45(6), 790-803. https://doi.org/10.1093/scipol/scy020

Mansfield, E. (1995). Academic research underlying industrial innovations: Sources, characteristics, and financing. Review of Economics and Statistics, 77(1), 55-65.

Mansfield, E., \& Lee, J. Y. (1996). The modern university: Contributor to industrial innovation and recipient of industrial R\&D support. Research Policy, 25(7), 1047-1058.

Mowery, D. C., Nelson, R. R., Sampat, B. N., \& Ziedonis, A. A. (2001). The growth of patenting and licensing by U.S. universities: An assessment of the effects of the Bayh-Dole act of 1980. Research Policy, 30(1), 99-119. https://doi.org/10.1016/S0048-7333(99)00100-6

Muscio, A., \& Pozzali, A. (2013). The effects of cultural distance in university-industry collaborations: Some evidence from Italian universities. Journal of Technology Transfer, 38(4), 486-508.

Perkmann, M., King, Z., \& Pavelin, S. (2011). Engaging excellence? Effects of faculty quality on university engagement with industry. Research Policy, 40(4), 539-552. https://doi.org/10.1016/j.respol.2011.01. 007

Perkmann, M., Salandra, R., Tartari, V., McKelvey, M., \& Hughes, A. (2021). Academic engagement: A review of the literature 2011-2019. Research Policy, 50(1), 104114. https://doi.org/10.1016/j.respol. 2020.104114

Perkmann, M., Tartari, V., McKelvey, M., Autio, E., Broström, A., D’Este, P., Fini, R., Geuna, A., Grimaldi, R., Hughes, A., Krabel, S., Kitson, M., Llerena, P., Lissoni, F., Salter, A., \& Sobrero, M. (2013). Academic engagement and commercialisation: A review of the literature on university-industry relations. Research Policy, 42(2), 423-442. https://doi.org/10.1016/j.respol.2012.09.007

Phan, P. H., \& Siegel, D. S. (2006). The effectiveness of university technology transfer. Foundations and Trends in Entrepreneurship, 2(2), 77-144.

Schartinger, D., Schibany, A., \& Gassler, H. (2001). Interactive relations between university and firms: Empirical evidence for Austria. Journal of Technology Transfer, 26, 255-268.

Shane, S. (2004). Encouraging university entrepreneurship? The effect of the Bayh-Dole Act on university patenting in the United States. Journal of Business Venturing, 19(1), 127-151. https://doi.org/10.1016/ S0883-9026(02)00114-3

Tartari, V., Perkmann, M., \& Salter, A. (2014). In good company: The influence of peers on industry engagement by academic scientists. Research Policy, 43(7), 1189-1203. https://doi.org/10.1016/j. respol.2014.02.003

Tartari, V., \& Salter, A. (2015). The engagement gap: Exploring gender differences in university-industry collaboration activities. Research Policy, 44(6), 1176-1191. https://doi.org/10.1016/j.respol.2015.01. 014

Thune, T., Reymert, I., Gulbrandsen, M., \& Aamodt, P. O. (2016). Universities and external engagement activities: Particular profiles for particular universities? Science and Public Policy, 43(6), 774-786. https://doi.org/10.1093/scipol/scw01

Thursby, J. G., \& Thursby, M. C. (2003). University licensing and the Bayh-Dole act. Science, 301(5636), 1052-1052.

Tijssen, R. J. W. (2012). Co-authored research publications and strategic analysis of public-private collaboration. Research Evaluation, 21(3), 204-215. https://doi.org/10.1093/reseval/rvs013

Todorovic, Z. W., McNaughton, R. B., \& Guild, P. (2011). ENTRE-U: An entrepreneurial orientation scale for universities. Technovation, 31(2-3), 128-137. https://doi.org/10.1016/j.technovation.2010.10.009

Traoré, N., \& Landry, R. (1997). On the determinants of scientists' collaboration. Science Communication, $19(2), 124-140$.

Ubfal, D., \& Maffioli, A. (2011). The impact of funding on research collaboration: Evidence from a developing country. Research Policy, 40(9), 1269-1279. https://doi.org/10.1016/j.respol.2011.05.023

Weerasinghe, I. M. S., \& Dedunu, H. H. (2020). Contribution of academics to university-industry knowledge exchange: A study of open innovation in Sri Lankan universities. Industry and Higher Education. https://doi.org/10.1177/0950422220964363

Zhao, Z., Broström, A., \& Cai, J. (2020). Promoting academic engagement: University context and individual characteristics. Journal of Technology Transfer, 45(1), 304-337. https://doi.org/10.1007/ s10961-018-9680-6

Publisher's Note Springer Nature remains neutral with regard to jurisdictional claims in published maps and institutional affiliations. 